\title{
INDUSTRIAL CLUSTERS - ENABLING ENVIRONMENT FOR INNOVATION, GROWTH AND SMART SPECIALIZATION
}

\author{
M. Kozhuharov* \\ Industrial Business and Entrepreneurship Department, Faculty of Economics, Trakia University, \\ Stara Zagora, Bulgaria
}

\begin{abstract}
The purpose the present report is to present the evolution of theoretical concepts and dynamics in the term "clusters". This article will explain what clusters and cluster networks are, describe their classification, their sectoral division and will present approaches to foster clusters and their establishment as competitive and sustainable structures. Because of the great economic success of clusters as a form of economic, political and educational cooperation between different in structure, scope and activity organizations a major emphasis will be placed mainly on the mechanisms for the realization of sustainable and intelligent growth energized by clusters and their networks, incentives for formation and key factors in the realization of their activity. The research also corroborates that the enabling cluster policies represent as powerful pathway and incentives, and support the creation of value added chain for companies while generating knowledge-producing customers. However, the focus remains over the relationship and interdependence among participants in the production and creating innovation process.
\end{abstract}

Key words: cluster concepts, cluster classification, competitive advantages, cluster policy.

\section{INTRODUCTION}

The concept of industrial clusters and their success in economic terms can be addressed from two very different perspectives. One is the historically documented development and success of various industrial clusters as an empirical phenomenon, which has already stretched over one hundred years. The other is the success of industrial clusters as a political approach to a stable developing economy contributing to the prosperity of the region in which they are developing.

The purpose of this article is to define and distinguish the concepts of cluster and industrial cluster based on a theoretical analysis, to examine the reasons for the formation and stages of their development, and to present available concepts for clusters classification. Also, the major characteristics and the relevant European policies on clusters are examined, together with the reason for their

*Correspondence to: Mihail Kozhuharov, Trakia University, Main Building, Studentski grad, Stara Zagora, Bulgaria, Tel: 00359899780550, e-mail: m.kojucharov@gmail.com introduction and methods for their implementation.

\section{THE CLUSTER CONCEPT}

The English term "cluster" means "bunch", "heap" or "agglomeration". This literal translation may be associated with the definition of clusters by Michael Porter. He defines clusters as "geographically concentrated, interconnected companies and institutions in a particular field. Clusters often extend downstream to channels and customers (vertical clustering) and laterally to manufacturers of complementary products (horizontal clusters) and to companies in industries related by skills, technologies, or common inputs (sectoral clusters). Many clusters include governmental and other institutions, such as universities, standardization agencies, think tanks, vocational training providers, and trade associations (1).

The cluster concept has a long history that is associated with Alfred Marshall.

As a prominent representative of the neoclassical economic school, he monitors and 
analyzes the economic area around London and concludes that the organizations and businesses in this area are interconnected by three main factors. These are the labor force, specialized suppliers and access to knowledge and information (2).

Marshall uses the term "industrial districts", to describe the advantage generated by locating the firms in the same geographical areas. This form of cluster is different from the concept of urban agglomerations, which includes companies from different areas and activities located in the same urban area, because the companies are carrying out similar or connected activities (3).

Interest in the regional grouping derives primarily from experience and researches made on industrial districts in Italy. They are characterized by a high concentration of small companies mainly in traditional manufacturing industries, as well as a clearly defined activities border between local companies, a high level of entrepreneurship and merging of social and economic life.

The terms cluster and industrial district (industrial cluster) are often used interchangeably, although in essence they cover two different concepts.

Schmitz defines clusters as "producer groups of identical or similar products in close proximity to each other" (4). His definition identifies the cluster with two defining characteristics: geographical concentration and sectoral specialization.

Compared to the concept of industrial districts, the dynamics of geographical concentration of companies leads to growth and organizational development, that allow to derive external economies of scale. Marshallian model of the industrial district emphasizes benefits, arising from economic relations and trade ties. Developed are also socio-economic models of industrial districts, connecting the business relations with social and institutional structures. Therefore industrial areas can be defined as clusters of companies within a particular industry, which have built networks with the local community and businesses so as to support the industries.

In the economic literature there is a similarity between the concepts of the industrial clusters, innovative clusters and cluster initiatives. The practical understanding for clusters is linked to agglomerations of companies, suppliers, related institutions, local and regional authorities.
INDUSTRIAL CLUSTERS -

OCCURRENCE REASONS, STAGES OF DEVELOPMENT AND

CLASSIFICATION

Occurrence reasons

Conditions that stimulate the grouping of companies in clusters within a given geographical area are not fully understood, but it can be identify three main factors that are strongly associated with their formation and development.

First, there are geographic factors. According to them, the concentration of companies of a certain location is considered as the ratio of the range of transport costs compared to production costs and regional demand conditions.

The second factor is the historical events. Of these often comes the attractiveness of the location nowadays. Once the process of cluster formation has started, its development follows the path of its historic dependence, enclosed in a certain specialization pattern (5).

Institutional frameworks are defined as the third main factor associated with the emergence of clusters. They provide legal social and political structures that determine the rules of interactions among people. Institutional frameworks have formal and informal structures. Formal structures include political and legal frameworks as constitutions, documents human rights, courts and structures for conflict resolution on matters related to social interaction. Informal structures are covering cultural attitudes and the common rules and procedures for the management of social interactions. Institutional frameworks affect costs for uncertainties related to business activities (6).

\section{Emergence and growth of clusters}

Historically the clusters usually go through periods of emergence, growth, decline and transformation. Despite existing differences in individual development of each cluster The Observatory of European SMEs has determined a model that includes six steps of development (7).

The reasons for the emergence of the cluster can often be traced to historical circumstances such as availability of raw materials, specific knowledge in organizations or specific needs of a certain group of geographically concentrated customers or companies. The location of companies or entrepreneurs, as well as the performance of some important new technological innovations that stimulate the growth of many others are also part of the 
factors indicating a favorable influence on the formation of connections between companies. Unforeseen circumstances may affect the development of the cluster. However, growth often occurs by some explicit location factors, in particular the long-term development of specific knowledge, which can be utilized in a new productive way (8). Emerging clusters can often be traced to past events that lead to a sudden rise of clusters in recent years. The first stage in cluster development often involves new business accompanying activities leading to geographical concentration of companies in almost the same production run. The agglomeration is followed by local competition, which is the major driver of innovation and entrepreneurship (9).

Secondly, after the agglomeration of firms is established, more external economies are gradually created, forming a cumulative process. The first external economies often include the creation of a set of specialized suppliers and service companies, often originating from vertical disintegration of firms and the creation of a specialized labor market (10). The evolution may lead to reduced costs for sharing of raw materials. The savings on production costs go from specialized suppliers (serving numerous local firms) to client companies, which then will derive benefit, not available for similar enterprises in less localized environment (11). Cost savings are observed by the presence of a pool of experienced and skilled workers.

As a third step, new organizations are formed to serve several firms in the growing cluster, such as educational organizations, specialized educational institutions and business associations. Organizations make progress in local collaboration, learning process and the dissemination of technological knowledge, as well as the creation of localized knowledge forms of key personnel in the local industry. An example of this is the creation of centers for real services that have specialized skills, such as market development, technology, strategy, etc. They are able to provide professional competence, which is often necessary for the realization of greater innovation, and which smaller companies can seldom acquire. The introduction of centers increases innovation capacity in the local network of small producers.

The development of external economies and the emergence of new local organizations increase public influence, prestige and attractiveness of the cluster. This can lead to a tendency of moving more businesses and skilled employees towards the cluster.

The fifth stage concerns the creation of assets referring to relationships that promote nonmarket dissemination of information and knowledge for example through informal cooperation and assistance for the coordination of economic activity. In this way developed regional clusters may contain formations of specific, differentiated and localized relations among people and organizations that are coordinated by routines or conventions that often only work in the context of proximity (12). Communication that contains flows of non-codified knowledge that is complex and uncertain, often include deep human relations, which in turn are stimulated by proximity between individuals, companies and organizations.

Despite of the possibility regional clusters to maintain their success for decades or become part of a new cluster, sooner or later they are entering a period of decline. This stage reflects the situation of technological, institutional, social and / or cultural "blocking" business behavior, despite the existence of the many socio-economic conditions, that have once made the region a basis for a particular industry. Clusters can fall into the trap of "rapid specialization". Cluster development can be directed to reinforce the old behavior and suppression of new ideas that lead to hazards related to the survival of the cluster in terms of technological and global economic climate change (9).

\section{Classification}

In practice different types of economic agglomerations are observed, which identify themselves as clusters, but the economic literature distinguishes several basic types. Markusen (13) makes the first classification according to the size of the clusters in the industry, under which are identified four main types: marshallian clusters, hubs and spoke, satellite platforms and stateanchored clusters.

Marshallian clusters. They include small and medium-sized organizations with strong relationships built between them, which are highly dependent on the synergistic effect of the cluster.

Usually the structure of Hubs and spoke is made up of several small, gravitating around a large enterprise companies that provide specialized and supporting products and services. The terms of cooperation shall be determined by the largest company. 
The participants in satellite platforms are branches or departments of medium and large companies with a minimum cooperation and commitment.

The latter category are "Stateanchored" clusters. They are formed by state companies that have built relationships with specialized suppliers. Their development is dependent on the methods of financing the public sector.

There are other cluster distinctions, but in most cases they may be referred to the Markusen typologies.

\section{MODEL OF COMPETITIVE ADVANTAGES}

The leading economist and professor at Harvard Business School Michael Porter published in 1990 his book "The Competitive Advantage of Nations", in which he presents a new theory of competitive advantages of nations and emphasizes the role of clusters as one of the engines of economic growth.

In it he describes the so-called diamond of competitive advantages, which is divided into four main components that make up the national environment, in which are competing local interconnected companies:

Factor conditions. They represent the position of the country in terms of production factors such as human, natural, intellectual, capital resources and infrastructure necessary to compete in an industry. The main emphasis occupies both individual factors and the combination of other resources.

Demand conditions. Domestic demand for goods and services produced by a particular industry or its segment is the second significant determinant of the competitive advantages of the country.

By acting on the scale effect, domestic demand determines the nature and speed of the development and adoption of innovations by local companies. Domestic demand is characterized by three essential features: segmental structure of demand or distribution demand of certain segments; competent and rigorous buyers and overtaking buyers' needs. Segmental structure of demand or distribution demand of certain segments. Relatively large market segments are subject to pronounced economic interest of national companies. They are considered to be profitable, as they provide high economies of scale, and stimulate the uptake of new products, which is a source of competitive advantage internationally.

Competent and rigorous buyers are pressuring local businesses to meet high standards in terms of quality and characteristics of the products and culture of commercial service. In this way local firms enter new and advanced segments, improve their products and become competitive.

Overtaking buyers'needs. The firms of a given country are gaining competitive advantage if the needs of domestic buyers for certain product or service arises in their own country earlier than abroad. This means that domestic demand provides an early warning indicator for the needs of customers, which over time will become widespread.

The nature of domestic demand for the product or service of the industry requires reporting of both quantity and quality of demand.

Related and supporting industries - are characterized by the presence or absence in the country of national proceedings, that are interconnected and have a high international competitiveness.

According to M.Portar the sectors in the economy of each country can be referred to one of the following groups: industries producing raw materials, semi-finished goods, capital goods; industries producing consumer goods (clothing, food, household goods, etc.); complementary industries such as transport, telecommunications, which provide a link between sectors and industries. The above groups contribute to the emergence of advantages in other sectors of national industry by providing an effective and fast access to expensive resources, facilitating the coordination of suppliers in internal market and facilitate absorption of innovation by consumers in national sectors. Firm strategy, structure, and rivalry. In this determinant are reflected specific national and sectoral conditions in which local companies are created, organized and managed, and the nature and intensity of inter-company competition in the internal market.

Porter indicates two additional variables that indirectly affect the diamond. These are chance events and the government.

Under chance events is meant destructive events beyond the control of the companies and governments that allow entry of new actors, exploiting opportunities arising from the changed structure of the industry.

The government can influence each of the determinants. Successful public policies might increase the chances of obtaining competitive advantages, but is not able to create them. 
These six factors promote or hinder the creation of competitive advantages of companies, clusters and nations. According to Porter, all conditions must be present and to be conducive for achieving global supremacy of the company or the industry in the country.

The Diamond model can be used by managers to determine whether the internal market can support and maintain a successful internationalization or to assess in which country to invest. The model helps entrepreneurs to decide where to start their next venture. Government officials can use the model as a guide to create a policy framework that supports a particular industry in the best way.

\section{CLUSTER POLICY}

The recognition of the positive impact of clusters on regional economies and the establishment of market and systematic failures that hinder their activities justifies the application of public measures to alleviate the development of clusters. It also accelerates cluster consolidation and update. The Policies that support the establishment and development of clusters usually stem from three different political trends (14):

- The Regional policies, which are trying to build competitive regions.

- The Innovation policies, which are trying to encourage public-private collaborative researches and to improve their commercialization.

- Industrial and corporate policies that are trying to support the common needs of companies and to increase the utilization of technology especially in SMEs (15).

\section{Smart specialisation}

"Smart specialization" is the concept of the new innovation policy of the European Union, which is intended to promote the efficient and effective use of public investment in research. The aim is to stimulate regional innovation to achieve economic growth and prosperity, allowing regions to focus on their strengths (16).

Smart specialization strategy must be built on the basis of detailed analysis of regional assets and technologies. It should include an analysis of potential partners in other regions and to avoid unnecessary duplication. Smart specialization should be based on a strong partnership between businesses, public organizations and educational institutions. These partnerships are essential to success.
To boost the concept of smart specialization, the European Commission announced the creation of the platform S3 release in 2010, entitled "Regional Policy contributing to smart growth in Europe 2020". This platform is designed to help the regions and Member States of the European Union in the development, implementation and review of regional smart specialization strategies and to help them to identify activities that add more value and offer the best chances to strengthen their competitiveness (17).

The S3 platform support EU countries and regions to develop, implement and review their scientific researches and innovations for smart specialization. The role of the S3 platform is to provide information, methodologies, expertise and advice to national and regional governments as well as to encourage mutual learning, trans-national cooperation and to contribute to academic debates about the concept of smart specialization (18).

\section{CONCLUSION}

The theoretical analysis of the literature shows that industrial clusters can be considered as a tool for improving national and regional competitiveness. Through them nations stimulate economic development, encourage cooperation between businesses, universities, research organizations, suppliers and the government in a particular geographical area. The interactive nature of industrial clusters stimulates innovation and acquisition of economic knowledge, which are the basis for generating future benefits, and provide favorable conditions for the creation and development of new small and medium enterprises, that extend and strengthen the region in which they are located.

\section{REFERENCES}

1. Porter, M.E., Clusters and the New Economics of Competition, Harvard Business Review, reprint number 98609, pp 78, November-December 1998.

2. DAN, M.C., Innovative Clusters: a solution for the economic development of Romania, Theoretical and Applied Economics, Volume XIX, No.9 (574), pp 5-16, 2012.

3. Boja,C., Clusters Models, Factors and Characteristics, International Journal of Economic Practices and Theories, Vol. 1, No. 1, pp 34-43, 2011.

4. Schimtz, H., On the clustering of small firms, IDS Bulletin, Vol. 23 No. 1, pp 64-9, 1992.

5. Antonelli, C., "The economics of pathdependency in industrial organisation", International Journal of Industrial 
Organisation, Vol. 15 No. 6, pp 643-75, 1997.

6. North, D., Institutions, Institutional Change and Economic Development, Cambridge University Press, Cambridge, 1990

7. Observatory of European SMEs, Regional clusters in Europe, Enterprise publications 2012/ No. 3 pp14-15, 2012.

8. Pinch, S. and N. Henry, Paul Krugman's Geographical Economics, Industrial Clustering and the British Motor Sport Industry. Regional Studies, Vol. 33, 9:815827, 1999.

9. Porter, M. (1998b), Clusters and Competition: New Agendas for Companies, Governments, and Institutions, in Porter, M. (1998), On Competition. Boston: A Harvard Business Review Book, pp $197-$ 288, 1998.

10.Storper, M. and Walker, R., The Capitalist Imperative. Territory, Technology, and Industrial Growth. Basil Blackwell, New York, 1989.

11.Harrison, B., Kelley, M.R. and Gant, J., Innovative Firm behavior and Local Milieu: Exploring the Intersection of Agglomeration, Firm Effects, and Technological Change. Economic Geography, 72, 3: 233-258, 1996.
12.Storper, M., The Regional World: Territorial Development in a Global Economy, Guilford Press, New York, 1997.

13. Markusen, A., Sticky places in slippery space: typology of industrial districts", Economic Geography, Vol. 72 No. 3, pp 293-313, 1996.

14.OECD (2007), Competitive regional clusters. National policy approaches, OECD, Paris, 2007.

15.Clusters in RIS3, <http://www.knowhub.eu/knowledge-

base/encyclopaedia/clusters-in-ris $3 . \mathrm{html} \geq$ (10 April 2015).

16.European commission, Smart specialisation,

$<$ http://ec.europa.eu/research/regions/index

_en.cfm?pg=smart_specialisation>

April 2015)

17.European commission, Innovation and growth, $<$ https://ec.europa.eu/jrc/en/sciencearea/innovation-and-growth $>\quad(12$ April 2015).

18.European commission, About S3 Platform, <http://s3platform.jrc.ec.europa.eu/activitie s> (12 April 2015). 